\title{
DENSIDADE URBANA E QUALIDADE DE VIDA: O CASO DO PROJETO PORTO MARAVILHA
}

\section{URBAN DENSITY AND WELFARE: THE PORTO MARAVILHA CASE}

\author{
Carlos Emmanuel Joppert Ragazzo* \\ João Marcelo da Costa e Silva Lima**
}

\begin{abstract}
RESUMO: não é intuitiva a relação entre densidade urbana e qualidade de vida. Mas é fato que o projeto de revitalização da região portuária do Rio de Janeiro tem por foco promover o adensamento da região. Por que esse adensamento é desejável, tendo em vista que, nos últimos anos, o processo de urbanização de muitas cidades brasileiras - como o Rio de Janeiro - tem sido caracterizado por baixas densidades urbanas? E, dando um passo à frente, por que vale a pena revitalizar áreas degradadas centrais? Para responder a essas perguntas, este texto não só traça as principais características da urbanização dispersa, o custo social que ela representa, e as principais características de áreas degradadas que tornam propícios esforços de revitalização, como também investiga a história de revitalizações urbanas no Brasil, buscando identificar como a discussão de densidade urbana se insere nas "rodadas" que esses projetos de revitalização experimentaram. Por fim, analisa os instrumentos jurídicos utilizados para promover revitalizações urbanas voltadas a proporcionar o adensamento urbano no Brasil.
\end{abstract}

PALAVRAS-CHAVE: Adensamento urbano. Áreas degradadas. Bem-estar urbano. Revitalizações urbanas. Urbanização dispersa.

ABSTRACT: The link between urban density and individual welfare is not obvious. That being said, Rio de Janeiro's project for the revival of the city's port area aims at fostering the area's urban density. Why is this desirable, considering that the urbanization process of many Brazilian cities including Rio de Janeiro - has been characterized by low densities? And, taking a step forward, why is it worth revitalizing central blighted areas? In order to answer these questions, this article not only identifies some main features of urban sprawl, the social cost it entails, and why blighted areas are attractive spaces for urban revival projects, but also goes through the history of urban revival projects in Brazil, looking to identify how the discussion on urban density fits the different phases of these projects. Finally, this article analyses the legal mechanisms used to carry out urban revival projects aimed at fostering urban densities in Brazil.

KEYWORDS: Urban density. Urban blight. Urban welfare. Urban revival. Urban sprawl.

\footnotetext{
* Professor Adjunto e membro do corpo permanente do Mestrado da Escola de Direito da Fundação Getúlio Vargas. Bacharel em Direito pela Pontifícia Universidade Católica do Estado do Rio de Janeiro (PUC/RJ), Mestre em Direito da Concorrência e Regulação de Mercados (LL.M) pela New York University School of Law (NYU), Mestre em Direito Civil e Doutor em Direito da Cidade pela Universidade do Estado do Rio de Janeiro (UERJ). E-mail: carlos.ragazzo@fgv.br

** Bacharel em Direito pela Escola de Direito do Rio de Janeiro da Fundação Getulio Vargas (FGV Direito Rio). Mestrando em Direito da Regulação pela Escola de Direito do Rio de Janeiro da Fundação Getulio Vargas (FGV Direito Rio). E-mail: joaomarcelocslima@gmail.com
} 


\section{INTRODUÇÃO}

Em 2009, o Rio de Janeiro finalmente tirou do papel um projeto que vinha sendo cogitado desde os anos de 1980: a revitalização da sua região portuária. Foi nesse ano que a Câmara dos Vereadores da cidade fluminense criou a Operação Urbana Consorciada da Área de Especial Interesse Urbanístico da Região Portuária do Rio de Janeiro (apelidada de Projeto Porto Maravilha), por meio da Lei Municipal n. 101/2009 ${ }^{1}$. Embora os objetivos imediatos do projeto tenham sempre estado claros (i.e., atrair investimentos e revitalizar o patrimônio histórico), não é particularmente óbvio o seu objetivo social e como ele se enquadra numa tentativa de redefinir o espaço urbano e a qualidade de vida na cidade.

Ao sancionar o Plano Diretor do Município do Rio de Janeiro, o prefeito Eduardo Paes chamou atenção para a necessidade de incentivar a ocupação residencial (i.e., promover o adensamento) da Zona Norte, Subúrbio e parte do Centro da cidade, pois "são áreas com boa infraestrutura urbana, mas que nos últimos anos sofreram um esvaziamento e uma deterioração” (NOTÍCIAS GUARATIBA, 2011). Assim, além de recuperar patrimônio histórico, o projeto visa induzir a aceleração da produção de áreas residenciais no Centro do Rio de Janeiro, de modo a incentivar pessoas a voltarem a morar lá.

Esse objetivo, no entanto, não é necessariamente intuitivo. Qual a relação entre densidade e bem-estar? Nos últimos anos, a população não tem justamente procurado ir para lugares com baixa densidade urbana, fugindo das regiões centrais? Para começar a investigar o adensamento urbano como medida de qualidade de vida, várias perguntas preliminares precisam ser analisadas: (i) nos últimos anos, o modelo urbanístico brasileiro tem privilegiado qual tendência: concentração ou desconcentração urbana? (ii) Quais os impactos dessa escolha? (iii) Como os processos de revitalização das grandes áreas centrais das cidades brasileiras se inserem na discussão da densidade urbana? (iv) Existem instrumentos jurídicos aptos a regular a densidade urbana em grandes centros?

\section{DENSIDADE URBANA E QUALIDADE DE VIDA NAS CIDADES}

Ainda existe muita dúvida sobre qual a densidade urbana desejável para maximizar o bemestar urbano. É possível que grupos sociais diferentes de um mesmo país percebam a questão da densidade de maneira diversa (ACIOLY; DAVIDSON, 2011, p. 8 et seq.). Além disso, cada cidade possui suas particularidades, razão pela qual a resposta à pergunta não pode ser direta, nem

\footnotetext{
${ }^{1}$ Dentre as principais obras do projeto, está a reurbanização de calçadas, reconstrução de redes de infraestrutura urbana (água, esgoto, drenagem), o plantio de 15.000 árvores e a construção de três novas estações de tratamento de esgoto.
} 
conclusiva. Para dar alguns exemplos práticos de diferenças que influenciam na decisão: (i) a demanda por transporte pode ser maior em determinadas zonas de centros urbanos; (ii) o nível de renda dos indivíduos - cuja variação geográfica não é a mesma em todas as cidades - poderá impactar a quantidade de carros nas ruas e, direta ou indiretamente, a escolha de modal²; (iii) há regiões em que o número de moradores por domicílio é maior do que em outras ${ }^{3}$; (iv) há regiões mais “comerciais” do que as demais, razão pela qual algumas terão concentração de escritórios maior do que outras. Além dessas, há inúmeras características que alteram a composição do que pode ser compreendido como a densidade desejável de uma região.

Há, de fato, uma série de diferenças claras entre cidades, o que torna extremamente difícil (e talvez até infrutífero) tomar uma medida de densidade demográfica única e, a partir dela, orientar o planejamento urbano tendo por propósito melhorar a qualidade de vida das pessoas. No Brasil, por exemplo, as estimativas de “densidade desejável” para maximizar o bem-estar urbano variam de 100 a 450 habitantes por hectare, a depender do autor ${ }^{4}$.

\subsection{A TENDÊNCIA MUNDIAL DA DESCONCENTRAÇÃO URBANA}

Não obstante, desde o século passado, as grandes cidades do mundo vêm se expandindo espacialmente, sem que a população urbana cresça na mesma proporção. Apenas a título exemplificativo, entre 1970 e 1990 a cidade de Los Angeles, Califórnia, experimentou aumento populacional de cerca de 45\%, enquanto sua área urbana teria expandido 300\% (MANCINI, 2008, p. 15). Verifica-se a mesma tendência em diversas outras cidades americanas ${ }^{5}$, mas não só lá: o fenômeno do espraiamento urbano também tem se manifestado em diversas regiões do mundo,

\footnotetext{
${ }^{2}$ De acordo com estudo do Ipea baseado em dados da Pesquisa Nacional por Domicílio (Pnad) de 2012 feita pelo Instituto Brasileiro de Geografia e Estatística (IBGE): (i) na faixa de renda de até um quarto do salário mínimo per capita, 28,2\% das famílias têm carro ou moto; (ii) na faixa de renda de até meio salário mínimo por pessoa, 35\% têm veículos privados; (iii) na faixa entre um e dois salários mínimos, 39,6\% têm carro, 10,6\% têm moto e 11,4\% têm os dois; e (iv) na faixa de renda de mais de cinco salários mínimos, 76,6\% têm somente carro, 1,2\% apenas motocicleta e 10,8\% têm ambos (G1 BRASIL, 2013).

${ }^{3}$ De fato, o Censo 2010 do IBGE revelou que a região Norte do Brasil, com 4 moradores por domicílio, é a que apresenta a maior média, ao passo que as regiões Nordeste e Sul têm, respectivamente, 3,5 e 3,1 moradores por domicílio (BULCÃO, 2011).

${ }^{4}$ Para Rodrigues (1986), por exemplo, o ideal é manter o nível de densidade acima de 100 habitantes por hectare. Já para Mascaro (1986, p. 61-68), o ideal é que a cidade se mantenha entre 379-455 habitantes por hectare.

5 Estima-se inclusive que áreas urbanas norte-americanas em geral tiveram um ritmo de crescimento que excedeu em pelo menos o dobro do crescimento de sua população (SIERRA CLUB, 2003). Mais surpreendente ainda é a estimativa de Richmond (2002), para quem a dimensão de áreas geográficas metropolitanas aumentou de cinco a dez vezes mais depressa do que a população (RICHMOND, 2002).
} 
como a Europa - cujas cidades foram historicamente associadas a um desenho urbano compacto ${ }^{6}$ e a América Latina (MANCINI, 2008, p. 18 et seq.) - incluindo o Brasil (REIS FILHO, 2006, p. 13; OJIMA, 2008, p. 49). Mais do que um fenômeno observável em cidades contemporâneas (em particular, as americanas, “símbolos” da urbanização dispersa), o sprawl é um processo relacionado ao estilo de vida enaltecido pela modernidade.

Por ter influenciado um número tão grande de cidades, o urban sprawl (ou urbanização dispersa) vem sendo muito estudado por economistas, urbanistas, formuladores de políticas públicas, entre outros membros da academia e da sociedade civil organizada. Há várias conceituações para o fenômeno, resultado da diversidade de perspectivas científicas por meio das quais ele é estudado. Mas, no limite, pode ser resumido na seguinte ideia: trata-se do desenvolvimento urbano caracterizado pela baixa densidade e por focar em áreas distantes do centro urbano (SNYDER; BIRD, 1998, p. 4). Assim, caracteriza-se pelo investimento na construção de propriedades imobiliárias em regiões distantes do centro urbano (BRUECKNER; HELSLEY, 2011, p. 205). Mas, o que terá causado esse fenômeno, especialmente se considerarmos a forma predominante de urbanização até a Revolução Industrial, marcada por uma separação tão clara entre área urbana e área rural (ARBURY, 2005)? A resposta a essa pergunta é extremamente complexa, e, por depender das particularidades socioeconômicas, históricas e políticas das cidades mundo afora, pode vir carregada de generalizações, sem o adequado lastro empírico. Entretanto, é possível encontrar alguns pontos em comum nos diferentes processos de urbanização experimentados pelas mais diversas cidades. Eles convergem nos grupos de “explicações” abaixo delineados.

\subsubsection{Razões para a propagação da urbanização dispersa: teorias urbanísticas}

Será que a teoria urbanística vem justificar os anseios e vontades da população, ou será que é o contrário: a teoria "pauta” as preferências das pessoas? Embora não seja possível, no caso, concluir por um caminho ou por outro, a verdade é que o anseio por se distanciar de grandes centros urbanos não é nada novo. A Revolução Industrial provocou o início do fluxo migratório generalizado de muitos grandes centros urbanos para regiões mais distantes da cidade, pois foi em razão dela que a parcela mais significativa de empregos disponíveis passou não mais a se localizar no campo, e sim nas cidades (GILLHAM, 2002, p. 93-95; ARBURY, 2005, p. 19). O caos urbano -

\footnotetext{
${ }^{6}$ Richardson e Chang-Hee (2004, p. 1) chegam inclusive a sugerir haver uma convergência nos padrões de povoamento urbano nos Estados Unidos e na Europa Ocidental. A respeito das especificidades do fenômeno na Europa, ver, e. g., OUESLATI et al., 2014.
} 
que já era ruim, e comprometia a qualidade de vida nas cidades - agravou-se significativamente, tornando-se insuportável para alguns segmentos da população.

Reagindo às condições cada vez mais degradantes das cidades, Ebenezer Howard desenvolveu, no começo do século XX, o conceito de Garden City. Seu objetivo era aprimorar a qualidade de vida das pessoas, principalmente por meio da desconcentração urbana. Em maior ou menor medida, muitas cidades aderiram à ideia, cujo slogan era Nothing gained by overcrowding especificamente adotado pela Town and Country Planning Association (SMITH, 2012, p. 172). Uma Garden City consiste em uma comunidade cercada por um cinturão verde, em um meio-termo entre campo e cidade. A proposta seria eliminar as desvantagens da grande cidade, trazendo para dentro dela ambientes “campestres”. Para tanto, seria necessário operar com baixas densidades, da ordem de 35-40 residências por hectare (NEWMAN, 1996, p. 90). A influência do movimento urbanístico foi tal que, posteriormente, identificou-se no conceito Garden City o bojo de uma tendência anglo-saxônica à baixa densidade urbana, que foi exportada para a maior parte dos países de língua inglesa (NEWMAN; HOGAN, 1981).

Cidades como Camberra, capital da Austrália, e Milton Keynes, no Reino Unido, ilustram essa tendência, a que diversas cidades latino-americanas também aderiram, influenciadas pelos conceitos de Garden City. No Brasil, esse movimento, ainda que mais tarde, também chegou. Goiânia, capital do estado de Goiás, é um dos principais exemplos. Na capital do estado de São Paulo, o bairro "Cidade Jardim” teve seu nome atribuído em razão de seu planejamento urbano fortemente influenciado pelos conceitos de Garden City.

As Garden Cities contribuíram para o surgimento e desenvolvimento de outro movimento urbanístico, mais recente e conhecido como Counterurbanization. Cunhado por Brian Berry, o movimento se caracteriza pela redescoberta e reavaliação de áreas rurais, de modo a torná-las áreas residenciais e espaços comerciais (BERRY, 1976a). O processo está, então, logicamente associado à migração da população urbana a periferias das cidades mais próximas, ou de fato localizadas dentro do campo (CHAMPION, 1998a). No entanto, o movimento de Counterurbanization não necessariamente significa que as cidades experimentarão queda populacional (CHAMPION, 1998b). O que é certo, porém, é que, por força da Counterurbanization, os níveis de densidade das áreas urbanas tendem a diminuir, e a malha urbana, a expandir (em direção a áreas antes rurais).

Uma das manifestações de Counterurbanization - conceito amplo e relativamente indefinido, que deve englobar qualquer forma de desconcentração populacional (BERRY, 1976b) é o conceito de Edge City (“cidade limite”). As Edge Cities representariam a "terceira onda” do American Way of Life, sucedendo a era da "suburbanização" - que ocorreu em especial após a 
Segunda Guerra Mundial - e, posteriormente, o Malling - desenvolvimento urbano ao redor de grandes centros comerciais, para orientar e incentivar um público consumidor cada vez maior (GARREAU, 1991). Elas ocupam áreas gigantescas, distantes e até certo ponto desconectadas do centro urbano (Central Business District), correspondendo, principalmente, a enclaves de alta renda onde se encontram as residências urbanas unifamiliares, com alto padrão de consumo (OJIMA, 2008, p. 50). Ao redor desses enclaves, quase todos os serviços encontram-se disponíveis (shoppings, empresas, etc.), fazendo com que as pessoas não mais tenham que se deslocar frequentemente para os centros urbanos.

A primeira Edge City - ou novo “centro de negócios” urbano - ocorreu em Detroit, nos Estados Unidos. Durante os anos de 1920, lá foi construído o Detroit's New Center, localizado cinco quilômetros ao norte do centro histórico da cidade. Depois desse primeiro projeto de expansão urbana - altamente dependente do uso do carro - diversas cidades americanas decidiram criar seus Edge Cities: Tyson's Corner, hub de empreendedorismo de tecnologia da informação na Virgínia, e Century Fox, na Califórnia, são apenas alguns exemplos. No Rio de Janeiro, o eixo Barra da Tijuca-Recreio dos Bandeirantes é a mais clara ilustração de uma Edge City.

\subsubsection{Razões para a propagação da urbanização dispersa: tecnologia}

Como discutido acima, as condições degradantes dos centros das grandes cidades, que se agravaram durante a Revolução Industrial (e que, em algumas cidades, estão longe de melhorar), levaram ao surgimento de teorias urbanísticas para apoiar a fuga de grande parte da população para regiões mais distantes. Nesse momento, a tecnologia também ajudou. O progresso científico do século XIX permitiu que engenheiros começassem a tirar do papel trens, bondes e outros veículos ferroviários que permitiriam a expansão espacial linear das cidades, antes compactadas simplesmente por falta de opção (NEWMAN, 1992). Cidades passaram a poder ter um raio de cerca de vinte a trinta quilômetros do centro financeiro (Central Business District), em vez de cinco quilômetros aproximadamente.

Mas, a tendência da dispersão urbana realmente só ganhou força com a popularização dos automóveis, o que ocorreu após a Segunda Guerra Mundial (NEWMAN, 1992, p. 287). O carro “liberou” as pessoas com condições de comprá-lo, reduziu custos de transporte e possibilitou que elas não precisassem mais viver tão próximas umas das outras e de seus empregos ${ }^{7}$. Essa é, aliás,

\footnotetext{
${ }^{7}$ Ver, a respeito de como o carro reduziu custos de transporte e possibilitou a expansão espacial das cidades, entre outros: ALONSO, 1964; JACKSON, 1985; BRUECKNER, 2000.
} 
uma das grandes razões pelas quais o carro foi retratado, durante boa parte de sua história comercial, como símbolo de status e de individualismo: do American Way of Life. Subir de vida significava sair do centro - áreas caóticas, barulhentas, violentas e onde se morava em apartamentos apertados - para a casa no subúrbio, onde pessoas da mesma classe poderiam conviver em harmonia $^{8}$. No Brasil, o que mais se aproxima desses subúrbios são os condomínios fechados das grandes cidades, os quais vêm rompendo com o padrão dicotômico centro-periferia/rico-pobre e tornam-se importante parâmetro brasileiro de ocupação do espaço urbano (OJIMA, 2008, p. 52).

\subsubsection{Outras razões para a propagação da urbanização dispersa}

Além dos fatores delineados acima - os quais não há como saber em que grau incentivaram, individualmente, a urbanização dispersa - há outros identificados pela literatura que encorajaram a demanda por propriedades cada vez mais distantes do centro, tais como: (i) mudanças de empresas para locais mais afastados da cidade, para reduzir custos e se expandir (SNYDER; BIRD, 1998, p. 5); (ii) a melhoria das estradas (BRUECKNER, 2000; MCGRATH, 2005;) e a construção de redes viárias ${ }^{9}$; (iii) regulamentações do uso do solo urbano (zoneamento urbano que exige a discriminação de áreas residenciais, comerciais e industriais) ${ }^{10}$; (iv) alguns aspectos geográficos (BURCHFIELD et al., 2006); (v) desconcentração (ou fragmentação) política (CARRUTHERS; ULFARSSON, 2002); (vi) violência urbana (MELGAÇO, 2012) e (vii) incapacidade de implementar uma política pública de planejamento urbano, i.e., quando a legislação que regula o planejamento urbano é ineficaz (BHATTA, 2010, p. 26).

\footnotetext{
${ }^{8}$ Sobre como a urbanização dispersa foi retratada como "estratégia" de segregação das classes norte-americanas "brancas" e mais abastadas (conhecidas como white flight), ver, e. g.: GILLHAM, 2002, p. 21; BRIGGS, 2005; HORTAS-RICO, 2013.

${ }^{9}$ No caso do Rio de Janeiro, por exemplo, a Autoestrada Lagoa-Barra, construída há cerca de 40 anos, contribuiu em grande medida para a produção habitacional de bairros da Zona Oeste da cidade, como São Conrado e Barra da Tijuca, e, mais recentemente, a Avenida das Américas e a Avenida Ayrton Senna favoreceram a ocupação do Recreio dos Bandeirantes e Jacarepaguá (FERREIRA, 2005). De acordo com Kleiman (2001), a construção da referida rede viária contribuiu para a segregação socioespacial característica da capital fluminense.

${ }^{10}$ Nas palavras de Arbury (2009, p. 24), referindo-se a regulamentações do uso de terra urbana (zoning), que foram inicialmente adotadas em Nova Iorque, em 1916, "Throughout the 80 years since zones were first introduced, they have been continuously refined into seemingly endless gradations of land use, often promoting low density development since the underlying philosophy of zoning continues to link back to its origin as a response to the excesses of the Industrial Revolution”. Nesse sentido, ver também: GLAESER; KAHN, 2004.
} 


\subsection{O ESVAZIAMENTO DAS REGIÕES URBANAS CENTRAIS}

A demanda por baixas densidades urbanas, quando não encontra limites, pode representar um custo social importante, não propriamente identificado como tal pela sociedade, mas relativamente cada vez mais visível no dia a dia das cidades, em especial nos grandes centros urbanos, o que deu origem, aliás, à discussão mais aprofundada sobre densidade. Nessas localidades, foi possível especular de forma inicial as externalidades negativas associadas ao processo de esvaziamento das regiões centrais nas demais áreas da cidade $^{11}$, tais como: (i) acirramento de congestionamentos; (ii) deterioração ambiental; (iii) aumento do custo de provimento de infraestrutura urbana (SNYDER; BIRD, 1998, p. 10-11); (iv) redução de interações humanas e, consequentemente, de capital social (PUTNAM, 2000; GILLHAM, 2002, p. 143-151) ${ }^{12}$; (v) segregação socioeconômica com, por exemplo, a criação de bairros mais distantes e “exclusivos” (IHLANFELDT, 1994) e (vi) prejuízo à saúde da população, sobretudo em razão do incremento dos níveis de obesidade (ZHAO; KAESTNER, 2009).

Isso porque não é clara a causalidade entre o fenômeno da dispersão urbana e o esvaziamento e consequente degradação de regiões urbanas centrais, o que é conhecido como blight $^{13}$. Em 1942, o economista Fisher (1942) havia voltado sua atenção para o fenômeno, e classificava como problemática a aceleração do êxodo populacional aos subúrbios, pois a expansão suburbana seria, predominantemente, uma resposta à migração de residentes de regiões centrais urbanas, e não tanto uma acomodação da população que estava indo do campo à cidade. Assim, se, em um primeiro momento, o que se viu foi um aumento vertiginoso da população urbana (em razão da Revolução Industrial), o segundo momento caracterizou-se por uma redistribuição da população existente (que fugiu para regiões mais distantes quando o crescimento das cidades já havia desacelerado).

Posteriormente, Breger (1967) contribuiu para a discussão, argumentando que o blight seria uma deseconomia do processo de urbanização, resultado das forças causais relacionadas ao progresso econômico e ao crescimento urbano, como, por exemplo, mudanças no uso do solo urbano, ascensão social de parcela significativa da população urbana, progresso tecnológico e a progressiva sobreutilização espacial de propriedades urbanas. Há pouco, Brueckener e Helsley publicaram estudo sustentando que as mesmas falhas de mercado do processo de dispersão urbana

\footnotetext{
${ }^{11}$ Para um excelente catálogo das externalidades negativas decorrentes do urban sprawl, ver: BHATTA, 2010.

${ }^{12}$ Recentemente, o argumento de Gillham e Putnam foi objeto de críticas: Brueckner e Largey (2006) testaram a sua hipótese empiricamente e chegaram à conclusão inversa dos referidos autores.

${ }^{13}$ A respeito da relação entre as causas atribuídas à urbanização dispersa e aquelas atribuídas ao esvaziamento de centros urbanos, ver: BREGER, 1967.
} 
resultaram na alocação ineficiente da população entre regiões centrais e periféricas, gerando o blight (BRUECKNER; HELSLEY, 2011) ${ }^{14}$.

Além de ser produto de uma alocação ineficiente da população, decorrente de falhas de mercado associadas à urbanização, há outro fator que muito contribui para o esvaziamento e degradação de regiões centrais: trata-se do "efeito vizinhança” (neighborhood effect), que influencia decisões individuais de manutenção de imóveis e reinvestimento e também, paralelamente, culmina em efeito dominó, provocando o declínio de toda uma região - em geral, central (BRUECKNER; HELSLEY, 2011). Explica-se: se uma casa está em mal estado, ou se fica vazia por muito tempo, ela reduz a atratividade de toda a vizinhança. Assim, a demanda pela região cairia. Nesse caso, haveria uma queda na lucratividade dos investimentos em manutenção dos proprietários dos imóveis da região. Novos imóveis então seriam largados ao descaso, com uma redução maior ainda de demanda. Esse processo, em última análise, levaria ao declínio de toda a região (BRADBURY et al., 1980).

No que tange especificamente ao Brasil, outro fator visto como causa do esvaziamento do centro é o processo de industrialização que ganhou força a partir da década de 1950 (TOLEDO, 2012, p. 34). Em um primeiro momento, as áreas centrais, ocupadas por porções significativas da população urbana influente, foram substituídas por instalações industriais ou de varejo (JANUZZI; RAZENTE, 2007, p. 148), processo acompanhado por uma concentração de pessoas de baixa renda nessas localidades, que lá encontravam residências próximas ao trabalho. No entanto, com o decorrer do tempo, essas atividades industriais perderam fôlego, razão pela qual também a população de baixa renda migrou da região, o que contribuiu para sua degradação ${ }^{15}$.

\footnotetext{
${ }^{14}$ Essas falhas de mercado seriam: (i) internalização imperfeita do custo social do trânsito (unpriced congestion) - as pessoas são incapazes de dimensionar as externalidades negativas geradas por seu uso particular do carro; (ii) internalização imperfeita das externalidades positivas geradas pelo espaço aberto dentro das cidades - os agentes de mercado dedicados ao setor imobiliário e a demanda por imóveis são incapazes de fixar o verdadeiro valor do espaço aberto e os benefícios (especialmente ambientais) a ele atrelados; (iii) internalização imperfeita do custo social que representa o provimento de infraestrutura - por serem serviços públicos, a obrigação de provimento de infraestrutura urbana é, via de regra, do Poder Público, razão pela qual obras privadas espaçosas não computam, em seu custo, aquele correspondente à instalação/complementação de uma rede de infraestrutura. Todas essas falhas contribuem para que o custo privado da urbanização dispersa seja significativamente inferior ao custo social.

${ }^{15}$ A recessão econômica, ocorrida entre meados de 1970/80, também contribuiu, ao ver de Hall (1998), para o desaparecimento de muitos empregos das regiões industriais. Consequentemente, diversas áreas urbanas privilegiadas, como zonas portuárias, foram relegadas e abandonadas.
} 


\section{REVITALIZAÇÃO DE ÁREAS CENTRAIS DEGRADADAS E ADENSAMENTO URBANO}

A essa altura do texto, cabe a seguinte pergunta: embora sejam convincentes os indícios de que o sprawl é um fenômeno que atinge não só cidades norte-americanas como também, à sua forma, as brasileiras, e embora se saiba que, em razão do sprawl, regiões urbanas centrais estão se esvaziando, por que devemos prestar atenção a essas informações? Ou melhor: qual é a relação pertinente que devemos estabelecer entre elas? A literatura especializada se esforça há anos para responder a essa pergunta, criando termos como Smarth Growth, Compact City e New Urbanism para se referir a movimentos urbanísticos centrados na ideia de que mais densidade urbana pode ser, sim, desejável ${ }^{16}$. As razões já começam a se tornar perceptíveis a olho nu.

Argumenta-se que altas densidades garantem a maximização dos investimentos públicos incluindo-se aí infraestrutura, serviços e transporte - ao mesmo tempo que permitem a utilização eficiente da quantidade de terra urbana disponível ${ }^{17}$. Outras externalidades positivas associadas a altas densidades são: (i) vitalidade urbana; (ii) facilidade de acesso aos consumidores (para empresas) e facilidade de acesso ao comércio (para indivíduos) (ZIEGLER, 2008, p. 8;); (iii) maior acessibilidade de emprego ${ }^{18}$ e (iv) redução de trânsito ${ }^{19}$. Ao se aceitar o argumento de adensamento, a pergunta seguinte é: onde adensar?

Por conta do processo de esvaziamento populacional, áreas degradadas tendem a se deteriorar, transformando-se em espaços ociosos e abandonados. No entanto, essas áreas são, em geral, caracterizadas pela presença de infraestrutura urbana, que antes servia às atividades comerciais e às residências nelas localizadas. Essa infraestrutura pode não estar em funcionamento, mas está construída e, em regra, volta a funcionar a um custo menor. Se, por um lado, áreas

\footnotetext{
${ }^{16}$ Para um catálogo desses movimentos, ver: MANCINI, 2008.

${ }^{17}$ Isso porque, como explicam Acioly e Davidson (2011, p. 29), a oferta de serviços públicos e infraestrutura urbana depende do número total de habitantes a ser servido dentro de um dado raio geográfico. Assim, baixa densidade se traduz em longas redes de infraestrutura em potencial estado de ociosidade para poucos consumidores, situação que resulta em altos custos de investimentos per capita tanto na instalação quanto na operação. A esse respeito, ver também: ZIEGLER, 2009, p. 173.

${ }^{18}$ Acioly e Davidson (2011, p. 23) esclarecem que alta densidade populacional significa alta acessibilidade tanto para empresas quanto para trabalhadores. Essa maior acessibilidade, por sua vez, significa maior competição e produtividade, com menos consumo de energia e tempo.

${ }^{19}$ Casado com o fenômeno da expansão urbana dispersa está o da dependência automobilística. Ao longo de boa parte do século passado, uma casa em um bairro de densidade baixa, longe do caos dos centros urbanos, representava "subir de vida”, o que significa que essa ascensão social não se completava sem a compra de automóveis, multiplicados exponencialmente. O automóvel era (e é) essencial para quem morava (ou ainda mora) em subúrbios marcados por baixa densidade urbana. Em razão da urbanização dispersa, de baixa densidade, as distâncias a serem percorridas pela população para acessar os mais variados serviços aumentaram - às vezes significativamente. Não é por outra razão que o planejamento urbano vai cada vez mais privilegiando o carro, que vira um símbolo do individualismo, da liberdade, de civilização, de progresso e de status social (NORTON, 2008). Evidentemente, isso agravou os congestionamentos urbanos.
} 
degradadas são revestidas de infraestrutura urbana, por outro, o fenômeno da urbanização dispersa disparou o custo de provimento de infraestrutura urbana e de serviços públicos, pois regiões urbanas de baixa densidade e crescimento linear acarretam diversas deseconomias. Baixas densidades são obstáculos para os benefícios da economia de escala na prestação de serviços, especialmente aqueles cujo fornecimento depende da expansão de uma rede já existente, como é o caso da água, esgoto, telefonia, energia elétrica e sistema viário. Ademais, devido aos baixos níveis de densidade, as distâncias entre emprego, residência e consumo tornam-se maiores, ocasionando mais tempo em transporte e, consequentemente, um aumento no custo de tarifas.

Isso significa que, desde sempre, os projetos de revitalização de centros urbanos degradados estiveram associados às iniciativas de adensamento populacional?

\subsection{A PRIMEIRA RODADA DE REVITALIZAÇÕES: PRESERVAÇÃO DO PATRIMÔNIO HISTÓRICO}

A resposta à pergunta do tópico anterior é simples: não. Desde pelo menos meados dos anos de 1970, determinadas áreas do Rio de Janeiro foram alvo de intervenção pública, com o intuito de recuperá-las. Nesse momento, o significado original de patrimônio histórico e cultural, que se limitava à proteção de bens, passou, com a Recomendação de Nairóbi de 1976 (um manifesto em reação à descaracterização do centro que estava começando a se sentir mundo afora, especialmente em razão da urbanização dispersa), a abranger também conjuntos arquitetônicos e paisagísticos urbanos ${ }^{20}$. Logo, passou-se a atribuir a determinadas regiões urbanas deterioradas um valor histórico e cultural alto o suficiente para justificar o investimento público em revitalização.

Um exemplo claro desse momento é o Projeto Corredor Cultural, implementado pela Prefeitura do Rio de Janeiro, com o apoio de diversos intelectuais, em 1979 (MACEDO, 2004, p. 15). O projeto, que se autodeclarava uma política pública voltada à preservação ou recuperação dos vínculos entre habitantes e memória urbana (PIO, 2001), levou à intervenção urbanística de três regiões do Rio de Janeiro: (i) o setor da Praça XV e imediações (Rua São José); (ii) o conjunto do Campo de Santana e (iii) os conjuntos nos quais se encontram parte do bairro da Lapa, Cinelândia e Largo Carioca. Durante toda a fase de execução, o projeto se concentrou na preservação dos conjuntos urbanísticos que a câmara e a equipe técnicas selecionaram por considerarem patrimônio

\footnotetext{
${ }^{20}$ De acordo com a referida Recomendação, "os conjuntos históricos ou tradicionais [...] constituem a presença viva do passado que lhes deu forma, asseguram ao quadro da vida a variedade necessária para responder à diversidade da sociedade e [...] constituem através das idades os testemunhos mais tangíveis da riqueza e da diversidade das criações culturais [...] diante dos perigos da uniformização e da despersonalização que se manifestam constantemente em nossa época” (ORGANIZAÇÃO DAS NAÇÕES UNIDAS..., 1976, p. 187).
} 
histórico e cultural. Não estava na agenda desse grupo de indivíduos reincluir moradores nas regiões centrais alvo de recuperação arquitetônica. Tanto é assim que, em 1976, apenas três anos antes da implementação do Projeto Corredor, entrou em vigor o Decreto Municipal n. 322/76, que vedava o uso residencial do núcleo central da cidade. Essa proibição só veio a ser revogada em 1994.

O legado mais conhecido hoje do Projeto Corredor é a revitalização da Lapa, bairro carioca famoso por diversos pontos de atração turística, como os Arcos da Lapa, bem como por albergar um dos mais ricos conjuntos arquitetônicos do Rio de Janeiro. Em 1970, antes do Projeto Corredor, várias ações de revitalização começaram a ser empreendidas na Lapa, como reformas e o tombamento de diversas edificações históricas, após mais de três décadas de franca decadência. O Projeto Corredor Cultural, que veio em seguida, identificou as diferentes nuances de preservação e renovação dos espaços, imóveis, atividades e usos, em função das características e potencial das áreas delimitadas pelo projeto. Com a entrada em vigor da Lei Municipal n. 506/1984, que criou a Zona Especial do Corredor Cultural, instituiu-se formalmente a revitalização. Desde então, a Prefeitura do Rio de Janeiro, uma das maiores incentivadoras do processo, investiu mais de seis milhões de reais em obras de revitalização de todos os projetos, concluídos no início de 2006. A iniciativa teve por foco apenas a preservação de edificações históricas, para assim estimular o turismo e o comércio noturno (JOSÉ, 2010), não se propondo a promover o adensamento urbano. Embora não tenha sido de todo um fracasso, o projeto não conseguiu propriamente reinserir a área no cotidiano carioca, tendo alcance residencial muito limitado.

Outras cidades brasileiras também tiveram seus centros históricos "revitalizados”, com ênfase na restauração e preservação do patrimônio histórico e cultural. É o caso, por exemplo, de Curitiba, que conheceu um significativo processo de esvaziamento populacional de seu centro histórico: entre 1980 e 2000, a população da região reduziu-se em 23\%. A revitalização do centro de Curitiba começou como parte do Projeto Cores da Cidade, que buscava "revalorizar e retomar a importância dentro do ambiente urbano central, buscando torná-los contemporâneos, harmoniosos e, por conseguinte, mais atrativos, em consonância com a própria imagem buscada do centro da cidade” (PROCOPIUCK; DALO, 2008, p. 324).

A execução do projeto envolveu intervenções rápidas sobre o patrimônio urbano e dependeu de exitosas interações entre o Poder Público e proprietários de imóveis de valor histórico e cultural. Na primeira fase, foram revitalizados 44 edifícios localizados entre as ruas Rio Branco e Riachuelo e a Praça Generoso Marques (conjunto arquitetônico conhecido como Arcadas do Pelourinho). O término dessa fase impulsionou a segunda, em que se recuperaram outras 47 
construções centradas no eixo Barão do Rio Branco-Riachuelo, entre a antiga Estação Ferroviária e o Passeio Público do centro histórico de Curitiba. Mais uma vez, percebe-se que o projeto de revitalização se concentrava em recuperar patrimônio histórico e cultural, melhorando, em última análise, a aparência do centro - tanto que a maior parceria do Projeto Cores da Cidade em Curitiba foi entre o Poder Público e a empresa Ypiranga, que forneceu tintas. Este primeiro momento da revitalização urbana do centro histórico de Curitiba é considerado, no agregado, um fracasso, em razão tanto da deterioração rápida dos imóveis recuperados, quanto do aumento da criminalidade na região (PROCOPIUCK; DJALO, 2008, p. 325).

Outros exemplos de revitalizações voltadas à preservação do patrimônio histórico podem ser citados, como é o caso do projeto de revitalização do Pelourinho, região do centro histórico de Salvador, que, embora tenha sido, no passado, um bairro ocupado pela elite da cidade, sofreu processo de franca deterioração a partir dos anos de 1970. Nos anos de 1990, o governo municipal se conscientizou da importância de preservar a região e reconheceu nela um enorme potencial para se tornar atração turística. Nesse contexto, o Instituto do Patrimônio Artístico e Cultural da Bahia (Ipac) publicou um documento em que traça os seguintes objetivos públicos a serem promovidos na região: (i) reabilitar e restaurar a área para torná-la atrativa ao turismo e (ii) criar condições para a preservação economicamente sustentável da região (NOBRE, 2002, p. 117). Não obstante, apenas 16\% das propriedades recuperadas tiveram destinação residencial (NOBRE, 2002, p. 119), embora a demanda por hotéis na área tenha aumentado 62\% entre 1981 e 1997 (NOBRE, 2002, p. 120). Ocorreu no Pelourinho um claro processo de gentrificação. O projeto de revitalização da região, ao invés de gerar um incremento, levou à redução de densidade: somente entre 1980 e 2000, a região perdeu $67 \%$ de sua população, obrigada a procurar moradia em outros lugares da cidade ${ }^{21}$.

Nota-se que são diversos os projetos de revitalização urbana no Brasil que tiveram por foco a preservação do patrimônio histórico e cultural ${ }^{22}$. Um número significativo das grandes metrópoles

\footnotetext{
${ }^{21}$ Ao analisar o processo de gentrificação do Pelourinho em Salvador, Nobre (2002, p. 120) comenta que "This reflects problems on regeneration strategies based only on economic activities, neglecting the housing potential of the area with disregard to contemporary urban design theory that since Jane Jacobs have considered high densities and mixed uses as an important way to promote sustainable development”.

${ }^{22}$ Mais recentemente, uma nova iniciativa do governo federal tem fomentado ações de revitalização de centros históricos brasileiros. Por meio de convênios entre municípios e a União Federal (termos de execução descentralizada), o Programa PAC Cidades Históricas, do Ministério da Cultura, atende atualmente 44 cidades, de 20 estados, disponibilizando um total de R \$ 1,9 bilhão até o final de 2014, sendo R \$ 1,6 bilhão para obras públicas. Além desse investimento, que vai para os cofres dos municípios selecionados, R 300 milhões são atualmente destinados a uma linha de crédito para proprietários de imóveis de cidades tombadas pelo Iphan. O Programa PAC Cidades Históricas surgiu como complementação ao Projeto Monumenta, também do Ministério da Cultura, que, atualmente, atende 26 cidades e tem por proposta (i) promover obras de restauração e recuperação dos bens tombados e edificações localizadas nas áreas do projeto e (ii) fomentar atividades de capacitação de mão de obra especializada em restauro, formação de agentes locais de cultura e turismo e promover atividades econômicas e educativas. Atualmente, o Projeto
} 
brasileiras, que estão em processo de degradação, vem sendo alvo de sucessivas iniciativas parecidas. São Paulo é outro caso: há tentativas de recuperação arquitetônica e paisagística do centro histórico da cidade desde os anos de 1970, quando se restauraram o Edifício Martinelli e o Teatro Municipal, entre outros monumentos da cidade (NOBRE, 2009, p. 223). E há inúmeros outros exemplos que poderiam ser trazidos à baila.

\subsection{A SEGUNDA ONDA DE REVITALIZAÇÕES: ADENSAMENTO URBANO}

Do tópico anterior foi possível extrair que, desde os anos de 1970, há uma série de políticas públicas federais, estaduais e municipais cujo objetivo é apenas a recuperação e manutenção do patrimônio histórico de grandes centros urbanos. Essas políticas, no entanto, não parecem ter sido muito eficazes. A capacidade de os municípios passarem a manter o patrimônio histórico recuperado por essas políticas é baixa, pois a dependência de recursos de terceiros (i.e., recursos que não são de moradores) inibe um ciclo virtuoso de investimento por parte dos residentes, dando vida à região (o que corresponderia ao oposto do efeito vizinhança). Outro ponto em comum dessas políticas é que nenhuma delas teve por foco o adensamento populacional. Uma possível explicação para isso é que, embora estudos especializados sobre a necessidade de adensar regiões, destinandoas tanto a uso residencial quanto comercial, já estivessem sendo publicados até antes dos anos de $1970^{23}$, ainda não haviam atingido a massa crítica, o que parece ter-se alterado nos últimos anos.

E, embora ainda persistam dúvidas a respeito da medida certa de densidade urbana (i.e., aquela que maximiza o bem-estar), já é possível notar que autoridades estrangeiras responsáveis pelo planejamento de cidades vêm cada vez mais implementando políticas públicas com o objetivo de adensar algumas áreas das cidades. Essas políticas públicas têm se concentrado em áreas urbanas centrais, que, em muitas cidades brasileiras, sofrem, há algum tempo, profundo processo de retração populacional $^{24}$.

Não à toa, as autoridades públicas brasileiras já iniciaram ações no sentido de revitalizar áreas centrais degradadas, desta vez não só focando em revitalização de patrimônio ou mesmo expansão de infraestrutura, mas também com ações direcionadas ao adensamento residencial. Para

Monumenta conta também com financiamento do Banco Interamericano de Desenvolvimento e com o apoio da Organização das Nações Unidas para a Educação, a Ciência e a Cultura (UNESCO). O objetivo do Projeto é fazer com que, a um só tempo, as cidades tenham seus centros históricos restaurados e dependam cada vez menos de recursos federais para sua conservação.

${ }^{23}$ Vide, e. g.: JACOBS, 1961.

${ }^{24}$ A título ilustrativo, os imóveis vagos já chegaram a 18\% do total de domicílios de toda a área urbana tanto do Rio de Janeiro quanto de Recife; em São Paulo, há pelo menos 400 mil domicílios vagos (em números arredondados), sendo que 50\% deles estão no centro da cidade (MORTARIE; EUZÉBIO, 2009). 
entender esse processo, que se iniciou com mais vigor na cidade do Rio de Janeiro, é importante retomar um pouco o histórico do esvaziamento central, o que dará mais clareza às razões que motivam a política de adensamento.

\subsubsection{Desconcentração Urbana no Centro Carioca}

No Rio de Janeiro, o êxodo populacional na área central é visto com muita clareza. Uma visita ao Palácio Imperial Quinta da Boa Vista, localizado no bairro de São Cristóvão, é altamente ilustrativa. Praticamente desde o início do século XIX, quando lá se instalou a família real portuguesa, até os anos de 1920, São Cristóvão foi o lar das mais eminentes famílias fluminenses e brasileiras. Atualmente, o bairro perdeu muito do que era, e muitas de suas áreas estão evidentemente degradadas. A população mais abastada foi, a partir dos anos de 1950, assentando-se em regiões próximas às praias cariocas: primeiro em Copacabana e, em seguida, Ipanema, Leblon, etc. São Cristóvão, por sua vez, começou a ser ocupado por fábricas de vestuário, entre outras atividades industriais que alteraram significativamente, a partir dos anos de 1920, a principal faceta do bairro. A crescente demanda por propriedades em regiões praianas da Zona Sul do Rio de Janeiro impulsionou um forte processo de investimento imobiliário nessas áreas. Essa tendência de superinvestimento localizado, que atraiu a maior parte do capital imobiliário da cidade, também acarretou o esvaziamento e declínio do centro carioca (ABREU, 1987, p. 114). Copacabana foi transformada no que alguns autores chamam de "subcentro" urbano - para lá foram diversas atividades de serviços, comércio de luxo e lazer que antes se encontravam na área central da cidade.

É possível supor que esse processo (de deslocamento da população carioca para regiões praianas) também tenha sido possibilitado pelo avanço tecnológico dos meios de transporte de distribuição de mercadorias. Muitas cidades foram construídas em volta de portos ou estações ferroviárias, enormes obras de infraestrutura com altos custos fixos e relevantes economias de escala, áreas essas que perderam muito do seu papel gravitacional, parcialmente eliminado por carros e caminhões, que permitiram a desconcentração da atividade comercial urbana (GLAESER; KAHN, 2004, p. 2.503). Isso contribuiu para que o Rio de Janeiro não precisasse mais se concentrar em torno da região portuária e da Estação Ferroviária de Leopoldina.

Mais recentemente, a expansão urbana do Rio de Janeiro tem-se concentrado na Área de Planejamento 4 (AP 4), que engloba a Barra da Tijuca e o Recreio dos Bandeirantes ${ }^{25}$, bairros

\footnotetext{
${ }^{25}$ A AP 4 é uma subdivisão administrativa do Município do Rio de Janeiro que compreende os seguintes bairros da Zona Oeste da cidade: (i) Jacarepaguá; (ii) Anil; (iii) Gardênia Azul; (iv) Curicica; (v) Freguesia; (vi) Pechincha; (vii)
} 
caracterizados pela urbanização dispersa. Entre 1970 e 2000, só a população da Barra da Tijuca aumentou 29,17\%. Isso explica o maciço investimento que o setor imobiliário tem realizado na região: apenas em 2004, 69,3\% das unidades lançadas em empreendimentos imobiliários na cidade eram localizadas na Barra da Tijuca (PREFEITURA DO RIO DE JANEIRO, 2007). E esse investimento é, na verdade, a resposta do mercado a uma preferência revelada pela população mais abastada, que surgiu como reação às condições cada vez mais degradantes de grandes centros urbanos, como o Rio de Janeiro, e criou um ciclo de retroalimentação da demanda por terras distantes do centro $^{26}$, junto com a internacionalização do individualismo e conforto popular, caricaturado como The American Way of Life $e^{27}$.

Grande parte da população carioca se direcionou para áreas mais distantes do centro (PREFEITURA DO RIO DE JANEIRO, 2007, p. 11), sobretudo para a Barra da Tijuca e o Recreio (AP 4), em especial para condomínios fechados, relativamente distantes uns dos outros. Enquanto a AP 4 cresce, sendo alvo do maior fluxo migratório da cidade do Rio de Janeiro ${ }^{28}$, como se verá abaixo, o centro histórico da cidade (AP $1^{29}$ ) sofreu significativa queda populacional. Entre 1970 e 2000, o Centro perdeu quase 27\% de sua população (PREFEITURA DO RIO DE JANEIRO, 2007, p. 2). Aliás, entre 1991 e 2000, a população da AP 1 decresceu 12,6\%, perdendo mais população do que qualquer outra região do Rio de Janeiro. Apenas para dimensionar os dados, o Centro, que perdeu diversas empresas para a Barra da Tijuca, como é o caso da Shell, Michelin e Volvo (FERREIRA, 2005) - razão, aliás, do aprofundamento do processo de esvaziamento urbano da área -, experimentou uma queda de 20,3\% em sua população. São Cristóvão, por sua vez, de 15,1\% (PREFEITURA DO RIO DE JANEIRO, 2007, p. 13).

\footnotetext{
Taquara; (viii) Tanque; (ix) Praça Seca; (x) Vila Valqueire; (xi) Barra da Tijuca; (xii) Joá; (xiii) Itanhangá; (xiv) Camorim; (xv) Vargem Pequena; (xvi) Vargem Grande; (xvii) Recreio dos Bandeirantes; (xviii) Grumari e (xix) Cidade de Deus.

${ }^{26}$ Diversos autores mostram que a urbanização dispersa tem custos muito significativos para as regiões urbanas centrais. Esses custos se devem às condições cada vez piores do centro das cidades, o que alimenta ainda mais a vontade da população de se afastar. A respeito dos custos da urbanização dispersa sobre os centros urbanos, ver: DOWNS, 1998.

${ }^{27}$ O American Way of Life molda a preferência das pessoas, que, de acordo com a literatura, passam a querer: (i) propriedades mais distantes do centro, em regiões mais amenas, menos densas e (ii) propriedades espacialmente maiores quando comparadas às do centro. Ver, a respeito da descrição da demanda por terra durante boa parte do século XX, quando se acirrou a urbanização dispersa: MARGO, 1992; GLAESER; KHAN, 2004. Sobre a relação entre a urbanização dispersa e o American Way of Life, bem como seu planejamento urbano das cidades do século XX, ver: GILLHAM, 2002.

${ }^{28}$ Estima-se que a AP 4 recebeu, entre 1991 e 2000, 17\% do total das migrações do município (PREFEITURA DO RIO DE JANEIRO, 2007).

${ }^{29}$ A AP 1 engloba os seguintes bairros: (i) Saúde; (ii) Gamboa; (iii) Santo Cristo; (iv) Caju; (v) Centro; (vi) Catumbi; (vii) Rio Comprido; (viii) Cidade Nova; (ix) Estácio; (x) São Cristóvão; (xi) Mangueira; (xii) Benfica e (xiii) Vasco da Gama.
} 
Após o processo de esvaziamento que durou até o final dos anos de 1990, a densidade populacional da região central teve alteração desprezível, ao passo que a região da Barra da Tijuca e do Recreio sofreu uma variação relativa bem significativa, embora mantenha números absolutos relativamente baixos, o que preserva a característica de região periférica.

Tabela 1: Variação de densidade populacional bruta por AP (n. em 1000)

\begin{tabular}{|c|c|c|c|}
\hline Região & $\begin{array}{c}\text { Densidade bruta } \\
\text { em 2000 }\end{array}$ & $\begin{array}{c}\text { Densidade bruta } \\
\text { em 2010 }\end{array}$ & $\begin{array}{c}\text { Variação de } \\
\text { densidade entre } \\
\text { 2000 e 2010 em \% }\end{array}$ \\
\hline AP 1 & 80 & 86 & $7,5 \%{ }^{31}$ \\
\hline AP 4 & 23 & 31 & $37,72 \%$ \\
\hline AP 2 & 99 & 100 & $1 \%$ \\
\hline
\end{tabular}

Fonte: Elaboração própria a partir de dados do Armazém de Dados da Prefeitura do Rio de Janeiro ${ }^{33}$.

Existem outras evidências de que o movimento em direção à AP 4 nada mais é do que um processo de urbanização dispersa. Em 2010, a soma das áreas comerciais e residenciais da região correspondeu a $1.573 .798 \mathrm{~m}^{2}$ (84,65\% residenciais), contra apenas $291.021 \mathrm{~m}^{2}$ (61\% residenciais) na Zona Sul carioca (AP 2). Na AP 4, há menos gente ocupando mais espaço do que na AP 2, característica típica de uma região marcada pela urbanização dispersa. A Tabela 2 elenca as percentagens de área de construção licenciada, por tipo de uso (residencial ou misto), demonstrando que há uma forte concentração residencial na região ${ }^{34}$.

\footnotetext{
${ }^{30}$ A AP 1 engloba os seguintes bairros: (i) Saúde; (ii) Gamboa; (iii) Santo Cristo; (iv) Caju; (v) Centro; (vi) Catumbi; (vii) Rio Comprido; (viii) Cidade Nova; (ix) Estácio; (x) São Cristóvão; (xi) Mangueira; (xii) Benfica; (xiii) Vasco da Gama.

${ }^{31}$ O ligeiro aumento recente de densidade experimentado pela AP 1 pode ser atribuído as obras de revitalização em algumas de suas sub-regiões como a Lapa e Saúde, entre outras medidas pontuais no Centro do Rio de Janeiro.

${ }^{32}$ Já a AP 2 engloba os seguintes bairros cariocas: (i) Botafogo; (ii) Flamengo; (iii) Glória; (iv) Laranjeiras; (v) Catete; (vi) Cosme Velho; (; (vii) Humaitá; (viii) Urca; (ix) Copacabana; (x) Leme; (xi) Lagoa; (xii) Ipanema; (xiii) Leblon; (xiv) Jardim Botânico; (xv) Gávea; (xvi) Vidigal; (xvii) São Conrado; (xviii) Praça da Bandeira; (xix) Tijuca; (xx) Alto da Boa Vista; (xxi) Maracanã; (xxii) Vila Isabel; (xxiii) Andaraí; (xxiv) Grajaú. Enquanto a densidade urbana de Copacabana, pertencente à AP 2, é de aproximadamente 32.784,1 habitantes por $\mathrm{km}^{2}$, a da Barra da Tijuca, localizada na AP 4, é de apenas 1.498,6 km². Dados disponíveis em: (SEBRAE-RJ, 2011a; SEBRAE-RJ, 2011b).

33 Dados extraídos da “Tabela 2944 - Habite-se - Número de certidões, áreas licenciadas por tipo, edificações licenciadas e unidades licenciadas por tipo, segundo as Áreas de Planejamento, Regiões Administrativas e Bairros Município do Rio de Janeiro - 2010”, Armazém de Dados da Prefeitura do Rio de Janeiro.

${ }^{34}$ As percentagens dizem respeito à dimensão total do Município do Rio de Janeiro (e. g.: \% que a área de construção licenciada de uso residencial da Área de Planejamento representa em relação ao total de área de construção licenciada de uso residencial no Rio de Janeiro).
} 
Tabela 2: Representatividade de áreas licenciadas para construção de uso misto e residencial, por AP (2007)

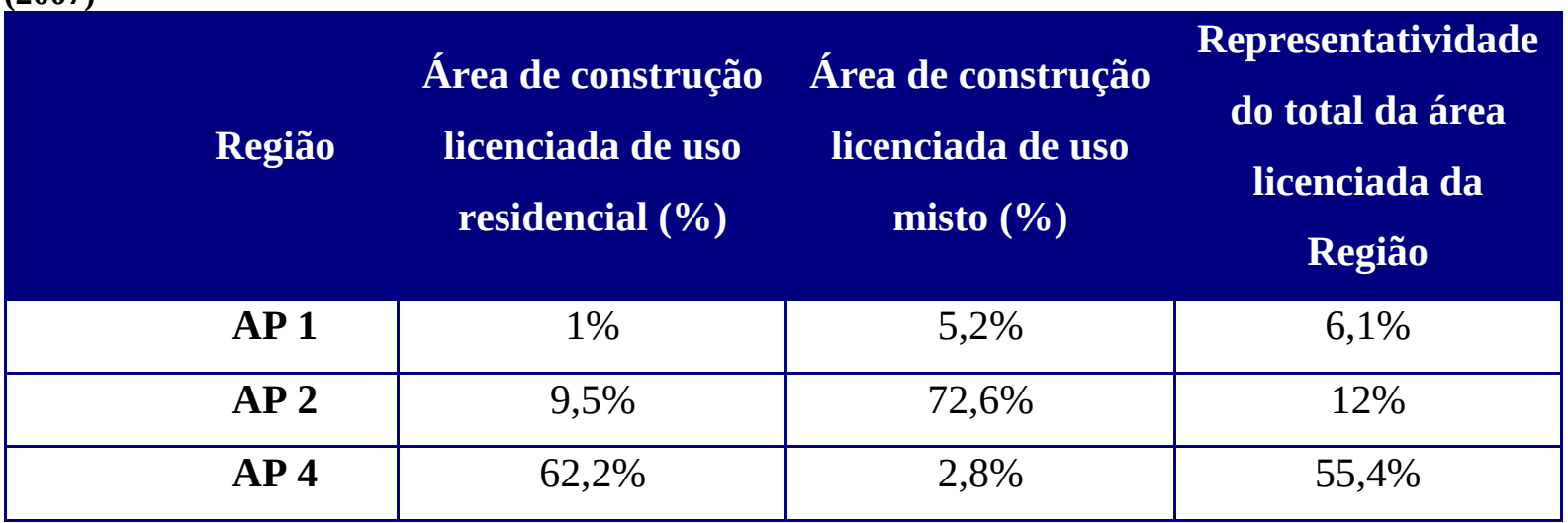

Fonte: Oliveira, 2008 (Ver Tabela 6 do autor).

\subsubsection{Razões para o Adensamento Urbano da Região Central do Rio de Janeiro}

Não há dúvidas de que a região central carioca se esvaziou ao longo dos anos. A pergunta, no entanto, é diferente: será que vale a pena adensá-la? Quais as vantagens?

Há uma série de razões que justificam o adensamento urbano do Centro do Rio de Janeiro. Em primeiro lugar, o padrão do uso do solo urbano da AP 1 é propício a assentamentos urbanos sustentáveis (i.e., que não gerem dependência automobilística, poluição e aumento dos custos de provimento de infraestrutura urbana). A região abriga apenas 1\% da área total de construção licenciada para uso residencial do Rio de Janeiro, contando, por outro lado, com 5\% da área total de uso misto da cidade, o que demonstra grande potencial para atrair mais comércio e, sobretudo, mais pessoas.

Além disso, o custo de oportunidade de adensar a região seria mais baixo em relação às demais áreas da cidade, já que a AP 1 possui uma malha de infraestrutura mais completa e relativamente subutilizada, sobretudo em relação à região para a qual a dispersão urbana parece terse direcionado (AP 4). Os dados de infraestrutura de esgotamento sanitário, que refletem o percentual de domicílios integrados ao sistema de canalização de águas residuais, constituem evidência bastante relevante nessa direção. 
Tabela 3: Domicílios particulares permanentes por tipo de esgotamento, segundo AP (2012)

\begin{tabular}{|c|c|c|c|c|}
\hline Região & $\begin{array}{l}\text { Número de } \\
\text { domicílios com } \\
\text { esgotamento } \\
\text { feito por rede } \\
\text { geral de esgoto } \\
\text { ou pluvial }\end{array}$ & $\begin{array}{c}\% \text { de } \\
\text { domicílios com } \\
\text { esgotamento } \\
\text { feito por rede } \\
\text { geral de esgoto } \\
\text { ou pluvial }\end{array}$ & $\begin{array}{c}\text { Número de } \\
\text { domicílios com } \\
\text { esgotamento } \\
\text { feito por outros } \\
\text { meios }^{35}\end{array}$ & $\begin{array}{l}\text { \% de domicílios } \\
\text { com } \\
\text { esgotamento } \\
\text { feito por outros } \\
\text { meios }\end{array}$ \\
\hline AP 1 & 97.723 & $93,32 \%$ & 2.293 & $6,68 \%$ \\
\hline AP 2 & 395.027 & $97,72 \%$ & 6.900 & $2,28 \%$ \\
\hline AP 4 & 247.190 & $82 \%$ & 53.385 & $18 \%$ \\
\hline
\end{tabular}

Fonte: Elaboração própria a partir de dados do Armazém de Dados da Prefeitura do Rio de Janeiro. ${ }^{36}$

Outro dado importante que confirma o argumento de custo de oportunidade se refere às redes metroviária e ferroviária, meios de transporte público urbano que, principalmente pelas características geográficas da cidade do Rio de Janeiro, têm dificuldades de expansão. Embora a AP 4 esteja recebendo investimentos para ampliação metroviária, grande parte da Barra da Tijuca não será servida por estações, sendo que os bairros do Recreio e de Jacarepaguá não têm previsão de qualquer rede. A região central, por outro lado, já tem uma infraestrutura em uso, recebendo diariamente quase um milhão de pessoas, das quais, por outro lado, um percentual nada desprezível utiliza veículos privados, ao invés de transporte público (seja por comodidade, seja por falta de transporte público de qualidade). Políticas de adensamento na região central poderiam ter fortes reflexos na redução de congestionamentos na cidade, tendo impactos positivos nos substanciais custos sociais que decorrem desse problema urbano.

\footnotetext{
${ }^{35}$ Essa expressão, “outros meios”, refere-se a formas de esgotamento que não são feitas por meio de um sistema de canalização de águas residuais mantido e gerenciado pelo estado e pelo qual se paga uma tarifa de serviço público. Exemplos de "outros meios": fossas sépticas, valas, etc.

${ }^{36}$ Dados extraídos da "Tabela 3169 - Domicílios particulares permanentes por existência de banheiro ou sanitário e esgotamento sanitário, segundo as Áreas de Planejamento, Regiões de Planejamento, Regiões Administrativas e Bairros - Município do Rio de Janeiro - 2010”, Armazém de Dados da Prefeitura do Rio de Janeiro.
} 
Tabela 4: Fluxo médio de passageiro das redes metroviária e ferroviária que acessam estações de trem e metrô por AP (2012)

\begin{tabular}{|c|c|c|c|c|}
\hline Região & $\begin{array}{c}\text { Metrô - } \\
\text { Média diária } \\
\text { (números } \\
\text { absolutos) }\end{array}$ & $\begin{array}{c}\text { Metrô - } \\
\text { Média diária } \\
\mathbf{( \% )}\end{array}$ & $\begin{array}{c}\text { Trem - Média } \\
\text { diária } \\
\text { (números } \\
\text { absolutos) }\end{array}$ & $\begin{array}{c}\text { Trem - Média } \\
\text { diária (\%) }\end{array}$ \\
\hline AP 1 & 183.000 & $36 \%$ & 109.000 & $40 \%$ \\
\hline AP 2 & 216.000 & $42 \%$ & 4.000 & $1,4 \%$ \\
\hline AP 4 & - & $0 \%$ & - & $0 \%$ \\
\hline
\end{tabular}

Fonte: Elaboração própria a partir de dados do Armazém de Dados da Prefeitura do Rio de Janeiro. ${ }^{37}$

Na verdade, a região central não somente alberga parte relevante dos postos de trabalho disponíveis na cidade, como também grande parte da infraestrutura e edificações-chave da cidade em inúmeras dimensões, ${ }^{38}$ como: (i) infraestrutura (a rede metroviária é apenas um ponto, já que a região abarca terminais ferroviários e rodoviários, além de porto e aeroporto); (ii) opções culturais (centros culturais, museus e teatros); (iii) esporte e lazer (com parques, estádios de futebol e sambódromo); (iv) instituições educacionais (importantes faculdades e colégios, públicos e privados); (v) hospitais federais, estaduais e municipais; (vi) vários prédios governamentais (incluindo a sede da prefeitura, além de consulados, polícia, assembleia, secretaria e afins) e (vii) forte comércio e empresas públicas. Toda essa gama de atrações não só incentiva o deslocamento cotidiano do carioca, causando trânsito, como também poderia ser acessada e/ou utilizada com maior intensidade, a partir de uma concentração maior de residentes na área.

\subsubsection{Instrumentos Urbanísticos de Controle de Densidade: a experiência do Projeto Porto Maravilha}

Superada a primeira rodada de revitalizações, e devidamente constatada a insuficiência da reforma sem uma política voltada para o adensamento das regiões centrais, a dúvida é a seguinte: de quais instrumentos jurídicos a autoridade pública pode fazer uso para atingir esse objetivo (i.e., trazer mais pessoas para morar em áreas centrais)?

Governos municipais, como a Prefeitura do Rio de Janeiro, têm à sua disposição um leque relativamente variado de instrumentos jurídicos oriundos do direito urbanístico para controlar os

\footnotetext{
${ }^{37}$ Dados extraídos da “Tabela 1268 - Fluxo médio de passageiros por dia nas linhas da Rede Metroviária - Município do Rio de Janeiro - 1995-2012”, Armazém de Dados da Prefeitura do Rio de Janeiro.

${ }^{38}$ Ao contrário da AP 4, que é mais caracterizada por áreas ambientais e polos industriais.
} 
níveis de densidade de suas cidades. Eles estão previstos no Estatuto da Cidade (Lei n. 10.257/01) ${ }^{39}$ - suporte jurídico de que dispõem os municípios que se propõem a enfrentar os problemas urbanos. O Estatuto concentra hoje instrumentos urbanísticos largamente utilizados no passado, mas também prevê alternativas regulatórias inovadoras, fruto de experiências de sucesso em gestão urbana em outros países. Mas, como influência do sprawl - chancelado em vários países até hoje -, é possível que alguns dos instrumentos jurídicos previstos no nosso ordenamento jurídico, à primeira vista aptos a promover o adensamento urbano de áreas degradadas via projetos de revitalização, não necessariamente tenham sido concebidos para esse propósito. É o caso, por exemplo, da outorga onerosa e da transferência do direito de construir ${ }^{40}$.

Para promover adensamento no Rio de Janeiro, a prefeitura do município está se valendo principalmente do instituto da Operação Urbana Consorciada (OUC). Uma OUC é um empreendimento urbano gerido pelo poder público municipal e implementado em parceria com a sociedade civil. A OUC pode ser parcial ou integralmente financiada pelas contrapartidas decorrentes da execução de um projeto urbanístico flexível "e traduzido num procedimento urbanístico orientado cumulativamente à transformação urbanística estrutural, à valorização ambiental e à promoção de melhorias numa determinada área do espaço habitável” (OLBERTZ, 2011, p. 131). Pelo elevado grau de interação entre poder público e iniciativa privada que pressupõem, operações urbanas consorciadas vêm, em geral (para não dizer sempre), acompanhadas de um incremento comercial na região atingida. É o aconteceu, por exemplo, em Puerto Madero, região portuária de Buenos Aires. Há 20 anos, Puerto Madero, que antes se resumia a um conjunto de galpões destinados à armazenagem de produtos e alimentos, foi revitalizado. Por meio de uma

\footnotetext{
${ }^{39}$ O Estatuto da Cidade, aprovado em 2001, é fruto de intensas negociações entre o governo e a sociedade civil. Além disso, trata-se de documento legislativo que consolida todos os instrumentos de que podem lançar mão autoridades públicas competentes para regular o planejamento urbano.

${ }^{40}$ A ideia por trás dos institutos reside na necessidade de compensar os proprietários de imóveis que devem ser conservados por força da legislação (imóveis de interesse histórico, ambiental, paisagístico ou cultural) e de imóveis cuja destinação se coaduna com os demais objetivos de interesse social previstos nos artigos 26 e 35 do Estatuto. Os referidos institutos não foram concebidos para promover adensamento, mas para controlá-lo (em níveis baixos, pois altas densidades nem sempre foram desejáveis) e para, ao mesmo tempo, preservar o patrimônio histórico (sobre a utilidade dos institutos para a preservação de patrimônio histórico urbano, ver: SANTIN, 2013). Por influência estrangeira, a concepção desses institutos no Brasil foi pautada na ideia de que era necessário gerar um custo para o adensamento - o que equivalia a desincentivá-lo (sobre a concepção dos institutos, simbolizada pela redação da Carta de Embu, de 1975, ver: GRAU, 1977). Assim, para que esses instrumentos sejam capazes de servir ao propósito de promoção de adensamento urbano, eles devem ser distorcidos ou literalmente ignorados (senão, terão o efeito contrário). É o que fez o Município do Rio de Janeiro ao aprovar a Lei Complementar n. 143/2014. A referida lei, que “incentiva a produção habitacional na Área de Especial Interesse Urbanístico da Região do Porto do Rio de Janeiro", será analisada abaixo em detalhe. Por ora, interessa apenas chamar a atenção para o art. 10: "As edificações residenciais e a parte residencial das edificações mistas ficam isentas de pagamento de contrapartida em caso de outorga onerosa do direito de construir e de alteração do uso”. Trata-se de isenção válida enquanto os incentivos da lei estiverem vigentes. A lógica por trás da isenção é justamente driblar os efeitos do controle de densidade (via imposição de custo para a verticalização de edifícios) característicos da outorga onerosa.
} 
operação urbana consorciada entre o poder público e a iniciativa privada, Puerto Madero abriga hoje o maior polo de lazer da cidade de Buenos Aires, contando com restaurantes, cinemas, museus, cafés, casas noturnas, hotéis e, recentemente, polos financeiros e residenciais.

O foco tradicionalmente comercial de OUCs é uma das razões pelas quais o instrumento é tão criticado pela literatura. Atribui-se à implementação de OUCs a causa de: (i) especulação imobiliária $^{41}$; (ii) segregação socioeconômica e gentrificação da área afetada pelo projeto de revitalização urbana ${ }^{42}$; (iii) graves violações aos direitos de moradores e comerciantes da região afetada, caso não sejam consultados e incluídos no processo de revitalização; (iv) desvio de finalidade, quando seu principal objetivo é a arrecadação, pelo estado, ou servir aos interesses do mercado (ou seja, situações de captura regulatória) e (v) inversão de prioridades, o que ocorre quando investimentos são alocados a áreas já privilegiadas, em detrimento de áreas mais necessitadas, i.e., quando operações urbanas consorciadas atingem áreas que não estão degradadas (OLBERTZ, 2011, p. 132). Como se pode perceber, os problemas associados a operações urbanas consorciadas remetem à (indevida) prevalência de interesses privados sobre a coletividade e, mais especificamente, sobre os moradores de baixa renda que residem e frequentam a área degradada atingida.

Aprovada a OUC por meio de lei municipal específica (Lei Municipal n. 101/2009, no caso do Projeto Porto Maravilha), que conterá o plano da operação urbana consorciada, o município poderá emitir Cepacs ${ }^{43}$. Esses Cepacs poderão ser negociados em leilões ou utilizados para financiar as obras da própria OUC. Importa ressaltar que, embora os Cepacs possam ser livremente negociados, devem ser exclusivamente convertidos na área atingida pela operação, por força de exigência prevista no art. 34, § 1, do Estatuto da Cidade. A possiblidade de emissão de Cepacs torna altamente atraente o investimento privado em operações urbanas consorciadas em parceria com o poder público. Via Cepac, o município cobra contrapartida dos investidores que pretendem utilizar o potencial construtivo adicional da região atingida por uma operação urbana consorciada; com os

\footnotetext{
${ }^{41}$ A especulação imobiliária é, de fato, uma das principais críticas feitas por urbanistas, acadêmicos e organizações nãogovernamentais ao Projeto Porto Maravilha, na região portuária do Rio de Janeiro (TOLEDO, 2012, p. 59).

${ }^{42}$ Rego (2010) alerta para o fato de o projeto de revitalização urbana de Puerto Madero, região portuária de Buenos Aires, Argentina, não ter sido capaz de integrar os stakeholders envolvidos, o que gerou uma verdadeira gentrificação da região.

${ }^{43}$ Os Cepacs correspondem à solução jurídico/econômica para viabilizar os investimentos em infraestrutura urbana. A ideia por trás desse instrumento jurídico é simples. Em linhas gerais, o governo emite (por lei) títulos que dão ao respectivo comprador o direito de construir (ou de mudar a afetação do imóvel, alterando, por exemplo, a finalidade, de residencial para comercial). Em outras palavras, garantem o direito do investidor de construir acima do potencial básico da área, mas dentro do limite máximo permitido pelo projeto (ou lei que autoriza a emissão dos títulos). O instituto dos Cepacs encontra-se previsto no art. 34 do Estatuto da Cidade.
} 
recursos arrecadados com essa intermediação financeira, realizam-se as obras e serviços de revitalização urbana.

É razoável supor que os investidores de uma operação urbana consorciada queiram certificar-se, antes de decidir se participarão do investimento, de que o projeto de revitalização urbana de fato sairá do papel. Para resolver esse aparente impasse de maneira eficiente, o município pode lançar mão de uma Parceria-Público-Privada (PPP) na modalidade de concessão administrativa, em que o parceiro privado deve adiantar ao estado recursos para a realização dos serviços e obras objeto da concessão. Isso torna possível que o município acelere o processo de revitalização urbana (e consequente desenvolvimento imobiliário) na região, o que sinaliza ao mercado que vale a pena investir nela. Nesse passo, acelera-se o processo de entrada de investimento imobiliário (por meio da aquisição de Cepacs), o que assegura a sustentabilidade financeira do projeto. No Projeto Porto Maravilha, é exatamente por isso que o município escolheu modelar uma PPP na modalidade de concessão administrativa, cujo objeto é o provimento dos serviços de revitalização e operação da Área Especial de Interesse Urbanístico da Região Portuária do Rio de Janeiro (Lei Complementar n. 105/2009).

Embora as OUCs não tenham sido unicamente concebidas para promover adensamento urbano de regiões degradadas, há maior compatibilidade (ao menos em tese) entre o instituto e esse objetivo $^{44}$. Não obstante, a experiência adquirida com os primeiros anos de implementação do Projeto Porto Maravilha demonstrou que a OUC, por si só, não tem sido suficiente para promover adensamento urbano, pois, por depender significativamente de financiamento privado, há um descompasso entre a percentagem de imóveis comerciais e residenciais da região, e a demanda dos investidores está concentrada em imóveis comerciais ${ }^{45}$.

\footnotetext{
${ }^{44}$ No entanto, não podemos deixar de notar que há alguns elementos de OUCs que podem comprometer sua capacidade de adensar regiões degradadas. Um exemplo seria a previsão do art. 33, V, do Estatuto da Cidade, que obriga toda lei específica que aprovar a OUC a conter Estudo de Impacto de Vizinhança (EIV). Trata-se de condição sine qua non para a obtenção das licenças ou autorizações de construção do projeto, além de requisito material da lei da OUC. O art. 37 do Estatuto da Cidade elenca as matérias que devem ser tratadas no EIV - uma delas é “adensamento urbano”, razão por que o impacto da OUC sobre adensamento populacional vira uma matéria importante nesses processos. O problema é que a importância dada pode ser favorável ao adensamento, mas pode muito bem ser desfavorável. Por força do art. 37, moradores ou terceiros interessados, descontentes com o impacto da OUC, podem, ao menos em tese, manifestar-se perante a prefeitura. Se essa manifestação seria contemplada pelo poder público na minuta final do EIV não é claro.

${ }^{45}$ Como bem nota Azevedo (2013): “Apesar de supostos projetos de incentivo realizados pela Prefeitura, que prometem garantir mais atratividade para construções habitacionais na Zona Portuária do Rio, o número de empreendimentos comerciais já se mostra claramente esmagador em comparação ao número de residências que serão construídas. De acordo com documento do Porto Maravilha, apenas sete 'lotes' estão destinados à construção de novos complexos residenciais em toda a região do Porto. Em comparação, o número de terrenos onde serão construídos edifícios e conglomerados comerciais ou institucionais já supera 20, mais que o triplo. Além disso, a área destinada para esse tipo de edificação é visivelmente superior. Quanto às edificações de uso cultural, apenas o Museu do Amanhã, além do Museu de Arte do Rio - já funcionando - está previsto para ser inaugurado na região. [...] De todos os novos
} 
De modo a corrigir essa tendência focada em imóveis comerciais do Projeto Porto Maravilha, foram editadas duas leis que estabelecem incentivos urbanísticos e fiscais para a produção habitacional na Região Portuária do Rio de Janeiro (Lei Municipal n. 5.780/2014 e Lei Complementar n. 143/2014, respectivamente), de modo a complementar a estratégia de adensamento traçada na OUC do Projeto Porto Maravilha (Lei Municipal n. 101/2009). A estratégia de gestão urbana formalizada nessas leis consiste em reduzir custos de produção de imóveis residenciais, para assim estimular pessoas a comprarem imóveis na Região Portuária. Assim, a Lei 5.780/2014 estabelece, por exemplo, que os imóveis que forem objeto de construção de novas unidades residenciais ou de transformação de uso para unidades residenciais estarão isentos de pagamento do Imposto sobre Propriedade Predial e Territorial Urbana (IPTU), da Taxa de Coleta Domiciliar de Lixo (TCL) e do Imposto sobre Transmissão de Bens Imóveis e de Direitos a Eles Relativos, Realizada Inter Vivos, por Ato Oneroso (ITBI). A Lei Complementar n. 143/2014, por sua vez, relaxa algumas exigências urbanísticas de edificações que normalmente pesam no custo de produção, tais como aquelas relativas a (i) apartamento de zelador; (ii) número de unidades por edificação; (iii) projeção máxima horizontal da edificação e (iv) área mínima de alojamento e vestiário para funcionários.

Os incentivos têm prazo de validade: cessam quando a metade do potencial de construção da região for utilizada para uso residencial. Estima-se que, por meio dos incentivos previstos nessas leis, 28 mil residências destinadas a várias faixas de renda sejam construídas na região, promovendo o adensamento urbano desejado.

\section{CONCLUSÃO}

Depois de um longo tempo priorizando empreendimentos distantes e justificando o afastamento da população para áreas periféricas, a dispersão urbana começa a ser questionada pelas autoridades públicas e por acadêmicos. Políticas de adensamento urbano começam a ser justificadas com base no incremento de qualidade de vida, sendo uma das chaves para o desenvolvimento das cidades no futuro ${ }^{46}$. Dentro desse contexto, as regiões centrais degradadas se mostraram como o

empreendimentos voltados para o setor residencial, apenas um foi comprado por imobiliária”. No final de 2014, a situação parecia ser semelhante (LIMA, 2014).

${ }^{46}$ Como bem nota Florida (2008), “Our public policy must work toward, not against, density. Nearly every expert on the subject agrees that innovation and productivity are driven by density. For the better part of a century, we've subsidized suburbanization. That stimulated consumption of cars and appliances, which drove the industrial economy and allowed families to buy affordable homes. But it also diffused the density that is increasingly required for innovation and growth. Of course, every place does not have to be like Tokyo or Manhattan. Silicon Valley-style 
candidato perfeito para ser o piloto dessa tendência, já que não possuem densidades elevadas, embora tenham, em algum grau, grande parte de infraestrutura mais pesada (rede de transporte e de esgoto) já instalada.

O Projeto Porto Maravilha está expondo esse conflito pouco óbvio, sendo um dos primeiros projetos no Brasil a relacionar adensamento à qualidade de vida urbana, em contraposição ao modelo de urbanização dispersa. Isso porque ele representa a superação de alguns paradigmas. De um lado, compreende que revitalizações urbanas meramente concentradas em projetos de recuperação de patrimônio histórico (que compõem a primeira rodada de revitalizações) têm escopo e duração limitados, ao impor custos administrativos e financeiros significativos, não sendo capazes de reinserir a região central da cidade de forma eficiente. E, de outro, acerta ao entender que essa reinserção parte de um princípio de fomento a residências, promovendo o adensamento urbano da área $^{47}$.

No entanto - e essa é outra lição do Projeto Porto Maravilha -, para promover adensamento urbano sustentável, a OUC isolada pode ser um instituto insuficiente, em razão de sua forte dependência de financiamento privado, que acaba naturalmente por priorizar investimento em imóveis comerciais. O êxito das medidas alternativas adotadas em 2014 pela Prefeitura do Rio de Janeiro, cuja estratégia se limita a reduzir custos de produção de imóveis residenciais, ainda é incerto. Será que preços mais baixos são suficientes para convencer a população a voltar a morar em regiões centrais, que até pouco tempo atrás eram degradadas e evitadas?

A experiência internacional sugere que isso é apenas metade do caminho. Há uma relação de interdependência econômica não desprezível entre centros urbanos degradados e outras regiões mais prósperas das cidades (VOITH, 1998), como os subúrbios americanos e a Barra da Tijuca no Rio de Janeiro. Como vimos acima, quando o investimento do setor imobiliário se concentra nessas regiões caracterizadas por urbanização dispersa, há subinvestimento nos centros urbanos; quando há reinvestimento em centros urbanos, toda a cidade - incluindo zonas de urbanização dispersa - é beneficiada. Não é eficaz, portanto, tratar os dois fenômenos urbanos - urbanização dispersa e degradação de centros urbanos - isoladamente, mas sim de modo complementar. Não é por outra razão que nos Estados Unidos, por exemplo, projetos de revitalização têm sido concebidos apenas

\footnotetext{
density would probably be sufficient. We can still have suburbs, but our economic policy has to start to encourage density, not sprawl".

${ }^{47}$ Vale notar que o Projeto Porto Maravilha não é o único no Brasil que se enquadra na "segunda rodada de revitalizações urbanas”. O projeto de revitalização da região portuária de Niterói, estado do Rio de Janeiro, também se encaixa na segunda rodada. Com efeito - e a título ilustrativo -, a Secretária de Urbanismo e Mobilidade da cidade já declarou que "acredita que 250 novos prédios poderão surgir no Centro, com aumento de 100\% da população da região, passando dos atuais 40 para até 80 mil pessoas” (ARAÚJO, 2013).
} 
como uma medida dentro de uma política pública urbana mais abrangente: Urban Containment Policies (UCP) ${ }^{48}$. A ideia por trás de UCPs é endereçar por completo o problema do crescimento das cidades: de um lado, a urbanização dispersa, e, de outro, a degradação de centros urbanos. Assim, os UCPs atuam simultaneamente em duas frentes: (i) incentivam a população a voltar a residir no centro (e a redução de custos de produção de residências é, aqui, uma estratégia) e (ii) criam desincentivos à urbanização dispersa.

O momento, no entanto, é de aguardar e verificar se as medidas de fomento à residencialização irão funcionar, já que o problema de habitação é bem mais complexo em países em desenvolvimento.

\section{REFERÊNCIAS}

ABREU, Maurício de A. Evolução Urbana do Rio de Janeiro. Rio de Janeiro: Instituto Pereira Passos/Prefeitura do Rio de Janeiro, 4. Ed., 1987.

ACIOLY, Cláudio; DAVIDSON, Forbes. Densidade urbana: um instrumento de planejamento e gestão urbana. Rio de Janeiro: Mauad Editora, 2ª Ed., 2011.

ALONSO, William. Location and Land Use. Cambridge: Harvard University Press, 1964.

ARBURY, Joshua. From Urban Sprawl to Compact City - An analysis of urban growth management in Auckland. 2005. 175 f. Dissertação (Mestrado) - Geography and Environmental Science Faculty, University of Auckland, 2005. Disponível em: <http://goo.gl/IGZFvd>. Acesso em: 12 jan. 2015.

ARAÚJO, Paulo Roberto. Câmara aprova polêmico plano de revitalização do Centro de Niterói. $O$ Globo, Rio de Janeiro, 27 nov. 2013. Disponível em: <http://goo.gl/Yhr3r1>. Acesso em: 6 mar. 2015.

AZEVEDO, Gabriella. Porto Maravilha corre risco de ficar deserto à noite e nos finais de semana. Jornal do Brasil, Rio de Janeiro, 26 out. 2013. Disponível em: <http://goo.gl/f61kUO>. Acesso em: 23 fev. 2015.

BERRY, B. J. L. Urbanization and Counterurbanization. Beverly Hills: Sage Publications, 1976a.

\footnotetext{
${ }^{48}$ Nas palavras de Hortas-Rico (2013, p. 3): “these policies combine regulations and incentives to guide and efficiently allocate new development as well as to balance the forces of decentralization and promote the revitalization of communities”. UCPs são declaradamente desenhados para limitar o uso de solo urbano fora de uma área urbana definida - uma região degradada, por exemplo. Ao mesmo tempo, UCPs também combinam regras de zoneamento de uso misto e de alta densidade, estratégias de habitação a preços acessíveis (reduzindo, em geral, custos de produção) e monitoramento da oferta de terra, junto com planos de investimento e incentivos de requalificação (NELSON et al., 2004).
} 
The counterurbanization process: urban America since 1970. In: BERRY, B. J. L. Urbanization and counterurbanization. Sage: Beverly Hills, 1976b, p. 17-30.

BHATTA, B. Analysis of Urban Growth and Sprawl from Remote Sensing. Springer: New York, 2010.

BREGER, G.E. The concept and causes of urban blight. Land Economics, v. 43, n. 4, nov. 1967, p. 369-376.

BRIGGS, Xavier de Souza. More Pluribus, Less Unum? The Changing Geography of Race and Opportunity. In: BRIGGS, Xavier de Souza. The Geography of Race and Opportunity: Race and Housing Choice in Metropolitan America. Washington: The Brookings Institution, 2005, p. 65-83.

BRUECKNER, J. K.; HELSLEY, R.W. Sprawl and blight. Journal of Urban Economics, v. 69, n. 2, mar. 2011, p. 205-213.

BRUECKNER, Jan K. Urban Sprawl: Diagnosis and Remedies. International Regional Science Review, v. 23, n. 2, 2000, p. 160-171.

BRUECKNER, Jan; LARGEY, Ann. Social interaction and urban sprawl. CESifo Working Paper, n. 1843, 2006. Disponível em: <http://goo.gl/I21qeM>. Acesso em: 6 mar. 2015.

BULCÃO, Luís. Censo 2010: Censo 2010: Brasil tem 3,3 moradores para cada domicílio. Terra: Cidades, Brasília, 29 abr. 2011. Disponível em: <http://goo.gl/E7txKu>. Acesso em: 5 mar. 2015.

BURCHFIELD, M.; OVERMAN, H.; PUGA D.; TURNER, M. Causes of Sprawl: A Portrait from the Space. The Quarterly Journal of Economics, v. 121, n. 2, maio 2006, p. 587-633.

CARRUTHERS, J. I.; ULFARSSON, G. F. Fragmentation and Sprawl: Evidence from interregional analysis. Growth and Change, v. 33, n. 3, dez. 2002, p. 312-340.

CHAMPION, A. G. Countraurbanization: The British Experience. In: Geographical Perspectives, n. 61. Salt Lake (US): University of Utah, 1998a, p. 15-29.

Studying counterurbanisation and the rural population turnaround. In: BOYLE, P.; HALFACREE, K. Migration into Rural Areas - Theories and Issues, Chichester: Wiley, 1998b, p. 21-40.

DOWNS, Anthony. How America’s City are Growing: The Big Picture. Brookings Review, v. 16, n. 4, Fall 1998, p. 8-11.

FERREIRA, Álvaro. A tendência ao esvaziamento da área central da cidade do Rio de Janeiro e sua associação com a implementação do teletrabalho pelas empresas. Scripta Nova (Barcelona), Web, v. 9, n. 194, 2005, p. 194(81).

FISHER, E. M. Economic Aspects of zoning, blighted areas and rehabilitation laws. American Economic Review, v. 32, n. 1, mar. 1942, p. 331-340.

FLORIDA, Richard. The Rise of the Mega-Region. Wall Street Journal, 12 abr. 2008, A8. 
G1 BRASIL. Mais da metade dos domicílios têm carro ou moto, diz Ipea. G1 Brasil, Brasília, 24 out. 2013. Disponível em: <http://goo.gl/GR5V1T>. Acesso em: 5 mar. 2015.

GARREAU, Joel. Edge City. Life on the New Frontier. New York: Doubleday, 1991.

GILLHAM, Oliver. The Limitless City: A Primer on the Urban Sprawl Debate. Washington: Island Press, 2002.

GLAESER, E. L.; KAHN, M. E. Sprawl and Urban Growth. In: HENDERSON, J. V.; THISSE, J. F. Handbook of Urban and Regional Economics, v. IV. Amsterdam: Elsevier, 2004, p. 2498-2527.

GRAU, Eros Roberto. Solo Criado/Carta de Embu. São Paulo: CEPAM - Fundação Prefeito Faria Lima, 1977.

HALL, P. Cidades do Amanhã: uma história do planejamento e do projeto urbano no século XX. São Paulo: Perspectiva, 1998.

HORTAS-RICO, Miriam. Sprawl, Blight and the Role of Urban Containment Policies. Evidence from US Cities. IEB Working Paper, n. 2013/002, 2013.

IHLANFELDT, Keith. The Spatial Mismatch between Jobs and Residential Locations within Urban Areas. Cityscape, v. 1, n. 1, nov. 1994, p. 219-244.

JACOBS, J. The Death and Life of Great American Cities. New York: Random House, 1961.

JACKSON, Kenneth. The Suburbanization of the United States. Oxford University Press, 1985.

JANUZZI, D. C. R.; RAZENTE, N. Intervenções Urbanas em Áreas Deterioradas. Semina: Ciências Sociais e Humanas, v. 28, n. 2, jul./dez. 2007, p. 147-154.

JOSÉ, Carlos Alberto Direito. A revitalização cultural da Lapa - RJ: uma análise da (re)estruturação espacial. Revista geo-paisagem (online), Ano 9, n. 17, jan./jun. 2010. Disponível em: <www.feth.ggf.br/Lapa.htm>. Acesso em: 4 mar. 2014.

KLEIMAN, M. Rede viária e estruturação intra-urbana: A prioridade dos investimentos na rede viária e seu papel na configuração das cidades: o Rio de Janeiro sobre rodas. Anais do IX Encontro Nacional da ANPUR, Rio de Janeiro, 2001, p.1596-1608.

LIMA, Ludmilla de. À espera de moradores: revitalização sem casas. O Globo, Rio de Janeiro, Caderno Rio, 25 dez. 2014, p. 6.

MACEDO, M. A. M. A concepção do Projeto Corredor Cultural do Rio de Janeiro: a participação de técnicos e intelectuais no processo de planejamento urbano. Anais do Seminário da História da Cidade e do Urbanismo, VIII, 2004, p. 1-15.

MARGO, Robert. Explaining the Postwar Suburbanization of the Population in the United States; the Role of Income. Journal of Urban Economics, v. 31, n. 3, maio 1992, p. 301-310. 
MASCARO, J. A forma urbana e seus custos. In: TURKIENICZ, B.; MALTA, M. Desenho Urbano: Anais do II SEDUR. São Paulo: Editora Pini, 1986, p. 61-68.

MANCINI, Gisele Arrobas. Avaliação dos custos da urbanização dispersa no Distrito Federal. 2008. 164 f. Dissertação (Mestrado) - Faculdade de Arquitetura e Urbanismo, Universidade de Brasília, 2008. Disponível em: <http://goo.gl/9yFDB2>. Acesso em: 5 mar. 2015.

MELGAÇO, Lucas de Melo. A cidade de poucos: condomínios fechados e a privatização do espaço público em Campinas. Boletim Campineiro de Geografia, v. 2, n. 1, 2012, p. 81-106.

MORTARIE, R.; EUZÉBIO, G. L. O custo do caos - Prejuízo ao bolso e ao meio ambiente cidades não suportam mais o crescimento da frota de veículos. Desafios do Desenvolvimento, Brasília, v. 53, n. 6, ago. 2009. Disponível em: <http://goo.gl/3yugv4>. Acesso em: 6 mar. 2015.

NELSON, A. C.; BURBY, R. J.; FESER, E.; DAWKINS, C. J.; MALIZIA E.; QUERCIA, R. Urban containment and central city revitalization. Journal of the American Planning Association, v. 70, n. 4, nov. 2004, p. 411-425.

NEWMAN, P. Reducing automobile dependence. Environment and Urbanization, v. 8, n. 1, abr. 1996, p. 67-92.

NEWMAN, Peter; HOGAN, Trevor. A review of urban density models: towards a resolution of the conflict between populace and planner. Human Ecology, v. 9, n. 3, set. 1981, p. 269-303

NEWMAN, P. The Compact City: an Australian perspective. Built Environment, v. 18 n. 4, 1992, p. 285-300.

NOBRE, Eduardo A. C. Urban regeneration experiences in Brazil: Historical preservation, tourism development and gentrification in Salvador da Bahia. Urban Design International (London Print), v. 7, n.2, 2002, p. 109-124.

. Políticas Urbanas para o Centro de São Paulo: renovação ou reabilitação? Avaliação das propostas da Prefeitura do Município de São Paulo de 1970 a 2004. Pós - Revista do Programa de Pós Graduação em Arquitetura e Urbanismo da FAU/USP, v. 16, n. 25, 2009, p. 214-231.

NORTON, Peter D. Fighting traffic. Boston: MIT Press, 2008.

NOTÍCIAS GUARATIBA. Eduardo Paes sanciona o novo Plano Diretor da cidade do Rio de Janeiro. Notícias Guaratiba, Rio de Janeiro, 4 fev. 2011. Disponível em: <http://goo.gl/3OYRR9>. Acesso em: 7 jan. 2015.

OJIMA, R. Novos contornos do crescimento urbano brasileiro? O conceito de urban sprawl e os desafios para o planejamento regional e ambiental. GEOgraphia (UFF), v. 10, n. 15, 2008, p. 46-59.

OLBERTZ, Karlin. Operações urbanas consorciadas. 2011. 141 f. Dissertação (Mestrado) Departamento de Direito do Estado, Faculdade de Direito da Universidade de São Paulo, 2011. Disponível em: <http://goo.gl/tNK0xO>. Acesso em: 6 mar. 2015. 
OLIVEIRA, Fabrício Leal de. Condicionantes territoriais para a elaboração de estimativas populacionais para unidades submunicipais: considerações a partir do caso do Rio de Janeiro. Coleção Estudos Cariocas (Prefeitura do Rio de Janeiro/Instituto Pereira Passos), jul. 2008. Disponível em: <http://goo.gl/mLbXrO>. Acesso em: 5 mar. 2015.

ORGANIZAÇÃO DAS NAÇÕES UNIDAS PARA A EDUCAÇÃO, A CIÊNCIA E A CULTURA - Unesco. Carta de Nairobi 1976. 19a Sessão. Nairobi, 1976. Cadernos de Sociomuseologia, n. 15, 1999, p. 187-208. Disponível em: <http://goo.gl/ODuAae>. Acesso em: 7 jan. 2015.

OUESLATI, Walid; ALVANIDES, Seraphim; GARROD, Guy. Determinants of Urban Sprawl in European Cities. Document de travail du GRANEM n. 2014-01-040, jan. 2014. Disponível em: <http://goo.gl/coeC5d>. Acesso em: 12 jan. 2015.

PIO, Leopoldo Guilherme. Cidade como patrimônio: Revitalização e preservação no centro histórico do Rio de Janeiro. 2000. Dissertação (Mestrado) - Instituto de Filosofia e Ciências Sociais, Universidade do Estado do Rio de Janeiro, 2000.

PREFEITURA DO RIO DE JANEIRO. Anexo Técnico I: Informações sobre todas as Áreas de Planejamento. Coordenação Operacional de Atendimento em Emergências. [2007]. Disponível em: <http://goo.gl/ZoEQPf>. Acesso em: 22 fev. 2015.

PROCOPIUCK, M.; DJALO, A. B. Comércio como fator de coesão dos centros urbanos: caso da revitalização comercial do Centro de Curitiba. Revista Turismo Visão e Ação (Eletrônica), v.10, n. 3, set./dez. 2008, p. 313-333.

PUTNAM, R. D. Bowling Alone. Simon and Schuster: New York, 2000.

REIS FILHO, Nestor Goulart. Notas Sobre a Urbanização Dispersa e Novas Formas de Tecido Urbano. São Paulo: Via das Artes, 2006.

REGO, Helena. Buenos Aires e o Puerto Madero. In: ANDREATTA, Verena. Porto Maravilha Rio de Janeiro + 6 casos de revitalização portuária. Rio de Janeiro: Casa da Palavra, 2010.

REVIT. Working towards more effective and sustainable brownfield revitalization policies. Interreg. Report, 2008. Disponível em: <http://goo.gl/xWR2AU>. Acesso em: 10 mar. 2014.

RICHMOND, Henry R. Sprawl and Its Enemies: Why the Enemies Are Losing. Connecticut Law Review, v. 539, n. 34, 2002, p. 539-566.

RICHARDSON, H. W.; CHANG-HEE, C. B. (Org.). Urban Sprawl in Western Europe and the United States. England: Ashgate, 2004.

RODRIGUES, F. Desenho Urbano: cabeça, campo e prancheta. São Paulo: Projeto, 1986.

SEBRAE-RJ. Informações socioeconômicas da região administrativa Barra da Tijuca. Rio de Janeiro, 2011a. Disponível em: <http://goo.gl/e5vwlV>. Acesso em: 9 mar. 2015.

. Informações socioeconômicas da região administrativa Copacabana. Rio de Janeiro, 2011b. Disponível em: <http://goo.gl/aRyDmg>. Acesso em: 9 mar. 2015. 
SIERRA CLUB. New research on a population suburban sprawl and smart growth. 2003. Disponível em: <http://goo.gl/EY0WBW>. Acesso em: 5 mar. 2015.

SNYDER, Ken; BIRD, Lori. Paying the costs of sprawl: using fair-share costing to control sprawl. Smart Communities Working Paper, dez. 1998.

SMITH, P. D. City: A Guidebook for the Golden Age. London: Bloomsbury, 2012.

SANTIN, Janaína Rigo. Estatuto da Cidade e Instrumentos de Política Urbana para Valorização do Patrimônio histórico, cultural, paisagístico e ambiental. Revista de Direito Ambiental, v. 70, 2013, p. 195-214.

TOLEDO, Mariana Peixoto de. Participação de Instituições Locais em Projetos de Revitalização Urbana: o Caso do Projeto Porto Maravilha na Cidade do Rio de Janeiro. 2012. 114 f. Dissertação (Mestrado) - Escola Brasileira de Administração Pública e de Empresas, Centro de Formação Acadêmica e Pesquisa, Fundação Getulio Vargas, 2012.

VOITH, R. Do suburbs need cities? Journal of Regional Science, v. 38, n. 3, ago. 1998, p. 445-464.

ZHAO, Zhenxiang; KAESTNER, Robert. Effects of Urban Sprawl on Obesity. NBER Working Paper, n. 15436, 2009. Disponível em: <http://www.nber.org/papers/w15436.pdf>. Acesso em: 27 jan. 2015.

ZIEGLER, E. H. The Case for Megapolitan Growth Management in the $21^{\text {st }}$ Century: Regional Urban Planning and Sustainable Development in the United States. The Urban Lawyer, v. 41, n. 1, Winter 2009, p. 147-182.

American Cities, Urban Collapse, and Environmental Doom. Planning; Environmental Law, v. 60, n. 1, jun. 2008, p. 7-8.

\section{PORTO MARAVILHA: URBAN DENSITY AND INDIVIDUAL WELFARE?}

ABSTRACT: The link between urban density and individual welfare is not obvious. That being said, Rio de Janeiro's project for the revival of the city's port area aims at fostering the area's urban density. Why is this desirable, considering that the urbanization process of many Brazilian cities including Rio de Janeiro - has been characterized by low densities? And, taking a step forward, why is it worth revitalizing central blighted areas? In order to answer these questions, this article not only identifies some main features of urban sprawl, the social cost it entails, and why blighted areas are attractive spaces for urban revival projects, but also goes through the history of urban revival projects in Brazil, looking to identify how the discussion on urban density fits the different phases of these projects. Finally, this article analyses the legal mechanisms used to carry out urban revival projects aimed at fostering urban densities in Brazil.

KEYWORDS: Urban density. Urban blight. Urban welfare. Urban revival. Urban sprawl. 
Recebido: 9 de março de 2015

Aprovado: 9 de junho de 2015 